\title{
O CLIPPING NA AVALIAÇÃO DOS RESULTADOS: UM GUIA PRÁTICO PARA PROFISSIONAIS DE RELAÇÕES PÚBLICAS
}

\author{
JONES MACHADO \\ UNIVERSIDADE FEDERAL DE SANTA MARIA \\ CAMPUS FREDERICO WESTPHALEN, RIO GRANDE DO SUL, BRASIL \\ JONESM2@OUTLOOK.COM
}

HTTP://DX.DOI.ORG/10.5902/2316882X25827 
O CLIPPING NA AVALIAÇÃO DOS RESULTADOS: UM GUIA PRÁTICO PARA PROFISSIONAIS DE RELAÇÕES PÚBLICAS

Resumo: Este artigo tem como tema o clipping, técnica envolvida no processo de avaliação das práticas de relações públicas, e visa discutir um modo consistente de avaliar a presença das organizações na mídia por meio de análise quantitativa e qualitativa. Tendo isso em vista, propõe-se neste estudo um guia prático para auxiliar, de forma didática, os profissionais nesta importante fase do processo de relações públicas.

Palavras-chave: avaliação de resultados; clipping; relações públicas.

EL CLIPPING EN LA EVALUACIÓN DE LOS RESULTADOS: UNA GUÍA PRÁCTICA PARA LOS PROFESIONALES DE LAS RELACIONES PÚBLICAS

Resumen: Este artículo presenta como tema el clipping, técnica involucrada en el proceso de evaluación de las prácticas de relaciones públicas, y tiene como objetivo discutir un modo consistente de evaluar la presencia de las organizaciones en los medios, mediante análisis cuantitativas y cualitativas. De este modo, se propone en este estudio un guion práctico para auxiliar, de forma didáctica, los profesionales en esta importante fase del proceso de relaciones públicas.

Palabras clave: evaluación de resultados; clipping; relaciones públicas.

\section{CLIPPING IN THE EVALUATION OF THE RESULTS: A PRACTICAL GUIDE FOR PROFESSIONALS OF PUBLIC RELATIONS}

Abstract: This article has the clipping as a topic, technique involved in the evaluation process of public relations practices and aims to discuss a consistent way to evaluate the organizations presence in the media through quantitative and qualitative analysis. With this intention, it is proposed in this study a practical guide to assist, didactically, the professionals in this important phase of the public relations process.

Keywords: evaluation of results; clipping; public relations. 


\title{
1 INTRODUÇÃO
}

Ao considerarmos as práticas de relações públicas pelo viés estratégico, devemos pressupor alguns aspectos que dão conta de tornar de fato tais práticas estratégicas. Nesse sentido, além da execução, todo trabalho de relações públicas não pode, portanto, prescindir do desenvolvimento de pesquisas, do processo de planejamento, do relacionamento com os públicos de interesse, de levar em conta a estratégia organizacional global, assim como não pode deixar de considerar a avaliação das práticas empreendidas. Sendo assim, tendo em mãos um plano de RP, oriundo de pesquisas e da avaliação de práticas anteriores, ele deve ser consistente em conteúdo e coerente com a realidade organizacional. Vale lembrar ainda que o processo de planejamento é pré-requisito para o estabelecimento de objetivos mensuráveis e indicadores de resultado do trabalho realizado. Por isso a sua importância, uma vez que para a área "Demonstrar seu valor para as organizações conseguirem alcançar seus objetivos e cumprir sua missão foi e continua sendo um desafio para as relações públicas" (KUNSCH, 2003, p. 358).

Tendo isso em vista, este artigo tem como tema o clipping, técnica envolvida no processo de avaliação das práticas de relações públicas, e visa discutir um modo consistente de avaliar a presença das organizações na mídia por meio de análise quantitativa e qualitativa, indo além do recorte de jornais. Nesse sentido, concordamos que

\begin{abstract}
Antes do "clipping", deve existir um planejamento calcado em bancos de dados inteligentes e no conhecimento profundo da empresa ou entidade, do mercado e da imprensa [...]. Depois do "clipping", deve existir um mecanismo que conduza a uma verdadeira auditoria do trabalho de relacionamento com a mídia e que, também, se respalde em um sistema de inteligência empresarial. (BUENO, 2012, p. 73)
\end{abstract}

Para isso, propõe-se neste estudo um guia prático para auxiliar, de forma didática, os profissionais nesta importante fase do processo de relações públicas. Como forma de sistematização, dividimos o artigo em quatro partes. Primeiramente, tratamos da função de avaliação em relações públicas, da prática de assessoria de imprensa, bem como da técnica do clipping e do processo de centimetragem. Na sequência, refletimos acerca do caráter estratégico do clipping para a comunicação organizacional.

Rev.Cad.Comun. Santa Maria, v.21, n.3, art 7, p. 127 de 143, set/dez.2017 
$\mathrm{Na}$ terceira parte, discorremos sobre a clippagem de matérias publicadas pela imprensa na ambiência digital. Já na seção quatro, propomos um roteiro para a avaliação anual de presença na mídia.

\section{O CLIPPING COMO INSTRUMENTO DE AVALIAÇÃO DE RESULTA- DOS}

Dentre as funções do profissional de RP - pesquisar, diagnosticar, prognosticar, assessorar, implementar programas planejados de comunicação, avaliar e controlar - a de avaliação é a que merece destaque aqui. Para o teórico das Relações Públicas, Roberto Porto Simões (2006, p. 7677), o "fazer" de relações públicas envolve "Avaliar e controlar: significa compreender o impacto das ações organizacionais e dos projetos de comunicação, permitindo verificar se o relacionamento está adequado ou se é preciso rever o plano de Relações Públicas ou as políticas organizacionais". Na mesma direção, segundo a pesquisadora Margarida Kunsch (2003, p.127), avaliação é função de Relações Públicas e consiste em "Avaliar os resultados dos programas obtidos na administração do processo de relacionamento das entidades com seus públicos".

E uma das táticas de estratégia que pode ser empreendida pelos relações-públicas consiste na assessoria de imprensa, que se baseia no relacionamento com a imprensa, mais especificamente com os jornalistas dos veículos de comunicação impresso, televisivo, radiofônico e digital. Isso se dá por meio do envio de press-kits (conjunto de materiais de divulgação referentes a um evento, por exemplo), press-releases (texto informativo a respeito de projetos que a organização está desenvolvendo, por exemplo), coletivas de imprensa, além de ações de calendarização (com a lembrança do aniversário do jornalista ou ainda com a realização de um "Dia da Imprensa" na organização).

O objetivo de tal relação é estreitar laços e sugerir temas de matérias para subsidiar o trabalho dos jornalistas a fim de auxiliar na pauta, apuração e reportagem. Feito isto, espera-se a publicação/veiculação de conteúdo positivo e favorável referente à organização na mídia, conferindo visibilidade para o trabalho desenvolvido, para a marca, para a organização assessorada ou para um serviço ou membro da organização. E para que esse processo se efetive, além de um release bem redigido, de um bom relacionamento com a imprensa, faz-se necessário o monitoramento e a

Rev.Cad.Comun. Santa Maria, v.21, n.3, art 7, p. 128 de 143, set/dez.2017 
avaliação do material publicado, de forma quantitativa e qualitativa.

Nesse momento entra em cena o $x$, técnica de RP que consiste no monitoramento, mensuração e avaliação das notas, citações, matérias, chamadas, etc. que são publicizadas pela imprensa a respeito da organização, sejam elas frutos de releases enviados pelos assessores de RP, ou não; a exemplo de denúncias, crises ou pauta criada pela própria imprensa. Esta verificação, além de servir para o acompanhamento do que é publicado sobre a empresa, presta-se também como fonte para auditoria de imagem e de mídia, permite o refinamento do trabalho de relacionamento com a imprensa e potencializa o aproveitamento de oportunidades a partir de matérias veiculadas. Veremos a seguir, passo a passo, como este instrumento de coleta de dados pode se transformar num ferramental estratégico para a gestão da imagem organizacional, a partir de um viés quantitativo e qualitativo.

Apresentaremos aqui um modelo passo-a-passo de como criar uma ficha para identificação, descrição e arquivamento do material coletado na mídia, para posterior utilização como subsídio às práticas de RP. Embora consideramos imprescindível o caráter qualitativo do clipping, também devemos ter em mãos os dados quantitativos do nosso trabalho, a fim de apresentarmos os resultados junto à direção e à presidência da organização assessorada. Para iniciarmos, tomamos como referência uma página de um jornal impresso em formato tablóide, cujas medidas são de $24 \mathrm{~cm}$ (largura) por 31cm (altura) em média.

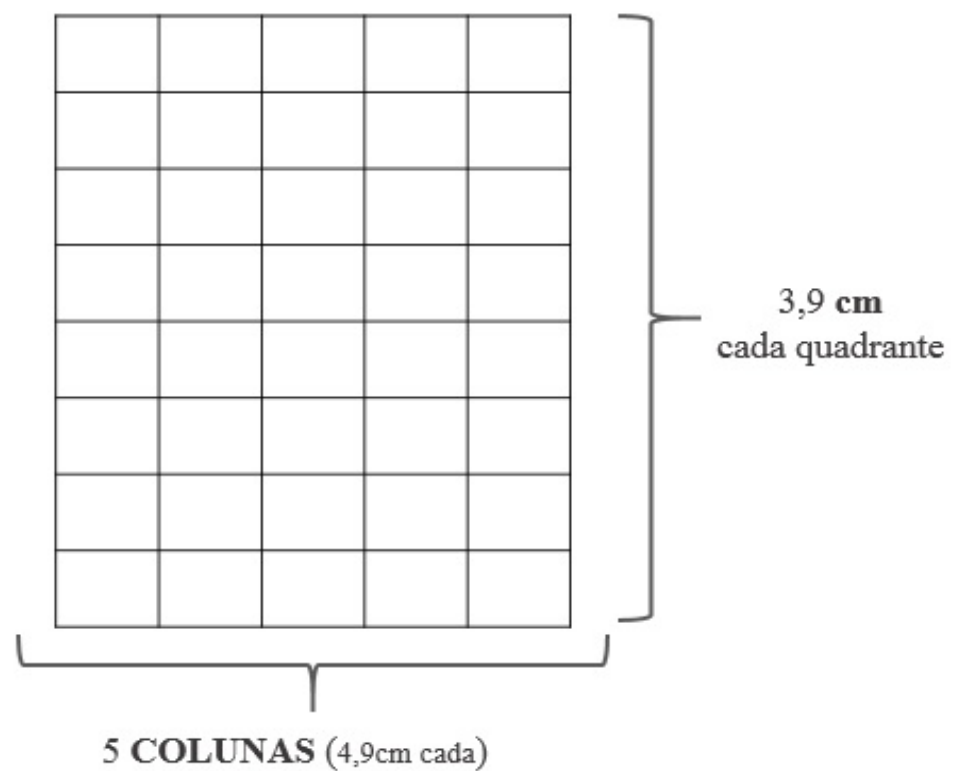

Figura 1 - Quadrantes do jornal impresso.

Fonte: elaborada pelo autor.

Rev.Cad.Comun. Santa Maria, v.21, n.3, art 7, p. 129 de 143, set/dez.2017 
Consideremos para o cálculo que cada página possui cinco colunas de largura e oito quadrantes de $3,9 \mathrm{~cm}$ cada um de altura. Para definirmos o valor que a matéria teria, caso tivesse sido publicada em forma de anúncio - e não por meio de release - procedemos ao seguinte cálculo:

\section{Valor da publicação: $\mathrm{n}^{\circ}$ de colunas $\mathrm{x} \mathrm{cm}$ x $\mathrm{R} \$$}

Aplicando a um exemplo (Figura 2), consideramos:

\section{Valor da publicação: $2 \mathrm{col} . \times 7,8 \mathrm{~cm} \times \mathrm{R} \$ 20=312,00$}

Para este cálculo, o valor de referência de custo do $\mathrm{cm} \times$ col (centímetro por coluna) foi de $\mathrm{R} \$ 20,00$. Este valor e suas variações - devido às editorias, capa e contracapa e espaços especiais, e dependendo do dia da semana - podem ser encontrados nas tabelas de preços fornecidas pelos veículos de comunicação.

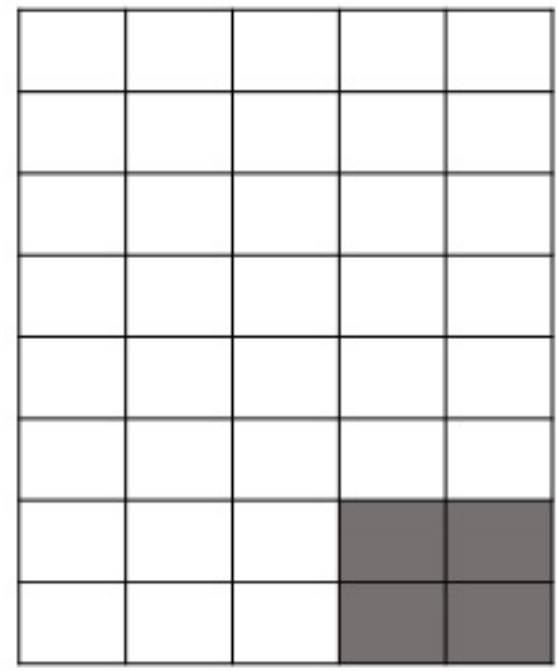

Figura 2 - Exemplo de localização de matéria publicada.

Fonte: elaborada pelo autor.

Para o cálculo de verificação de quanto custaria para cada leitor visualizar esta publicação, procedemos da seguinte forma:

\section{Custo por leitor: valor da publicação/tiragem}

Dessa forma, considerando o exemplo da Figura 2 e uma tiragem de 20.000 exemplares (obtida junto aos veículos de comunicação), temos: 
Custo por leitor: $312,00 / 20.000=R \$ 0,0156$ de centavos

E para verificarmos o valor para mil leitores, levamos em conta o seguinte cálculo:

\section{Custo por mil leitores: valor para cada leitor x 1000}

Aplicando ao exemplo da Figura 2 mais uma vez, temos que:

Custo por mil leitores: $0,0156 \times 1.000=R \$ 15,60$

No que se refere à precificação da matéria/nota/citação espontânea na TV e no rádio, consideramos basicamente o tempo e o preço específico de cada programa ou o horário veiculado. Para isso, aplicamos um cálculo de multiplicação do tempo de duração pelo valor do segundo de tempo de determinado programa. Estes valores de referência também são obtidos junto aos veículos de comunicação ou agências de publicidade e propaganda que atendem o assessorado.

Mas não basta saber calcular o valor do "centímetro por coluna"; a avaliação do clipping começa antes da interpretação dos dados e da emissão de um parecer baseado em informações úteis. Ela se inicia no momento da coleta das matérias/notas/citações, da identificação, da descrição e do arquivamento das publicações. Por isso, propomos como exemplo de roteiro para a avaliação da assessoria de imprensa a seguinte dinâmica:

1. Ronda diária de mídia: ao chegar na organização assessorada, ao iniciar seu trabalho de consultoria no home office ou até mesmo iniciar sua jornada numa empresa de monitoramento de mídia, a primeira atividade é fazer uma leitura geral de todos os veículos de comunicação elencados como prioritários do nosso cliente.

2. Descrição do material: tratamos de identificar todos os dados relevantes para descrever uma publicação sobre a marca na mídia. Para isso, cria-se uma ficha padronizada (ver Figura 3 e Figura 4) para cada tipo de mídia - impressa, televisiva, radiofônica e digital - com informações de data, veículo, página, editoria, jornalista res- 
ponsável, tamanho/tempo da matéria, além de outros dados como o enfoque dado, valoração qualitativa, local na página, forma de presença, impacto, título, chamada principal da edição, etc. e, ainda, a elaboração de uma súmula do conteúdo.

3. Informação aos gestores: caso haja algo relevante, positivo ou negativo, referente à organização assessorada ou aos concorrentes, deve ser reportado ao diretor da organização, por e-mail ou pessoalmente, com a cópia da matéria publicada em anexo ou em mãos. Aconselhamos a emissão profissional de um parecer com possíveis soluções, se necessário for, com vistas a orientar o assessorado a tomar decisões. Em alguns casos, pode ser preciso a realização de uma coletiva de imprensa, o pedido de uma errata ao veículo ou ainda tomadas medidas mais complexas.

4. Arquivamento: caso não seja necessária intervenção, ou então precise, mas apenas algum pequeno ajuste de ação pela equipe de comunicação ou de outros setores próximos, arquiva-se o material com vistas a utilizá-lo na elaboração do relatório anual de presença na mídia e no processo de planejamento do ano seguinte, tomando-o como base.

Abaixo, sugerimos um modelo de ficha para coleta, descrição e arquivamento das informações relacionadas à presença na mídia impressa. Este documento e os demais, usados para coletar dados oriundos de métricas predefinidas, servirão de suporte para a avaliação das práticas de relações públicas e as ações de assessoria de imprensa, assim como para a tomada de decisões e auditorias de mídia e de imagem futuras. 
CABEÇALHO COM IDENTIFICAÇÃO DA ORGANIZAC̣ÃO ASSESSORADA

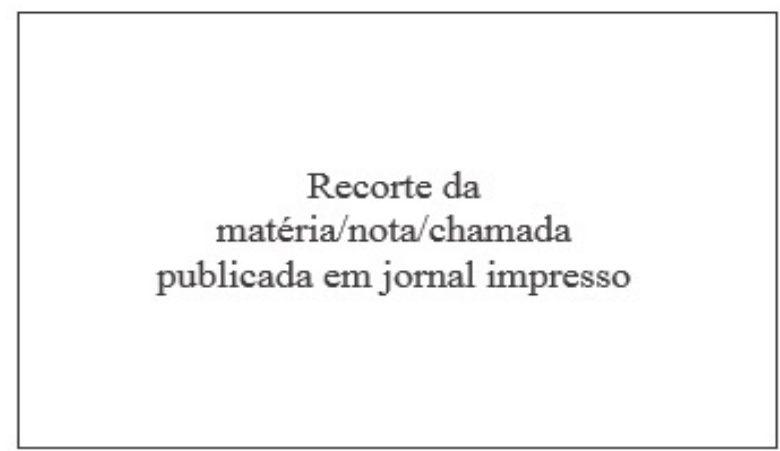

Data: / / . ( ) Sab/dom ( ) Seg ( ) Ter ( ) Qua ( ) Qui ( ) Sex Chamada principal da edição:

Veículo de Comunicação:

Cidade:

Título:

Editoria:

Jornalista responsável:

Página:

Súmula:

Medida: $\mathrm{cm} x$ col

Imagem: ( ) $\operatorname{Sim}($ ) Não

Enfoque: ( ) Positivo( ) Neutro ( ) Negativo

Impacto: ( ) Positivo ( ) Neutro ( ) Negativo

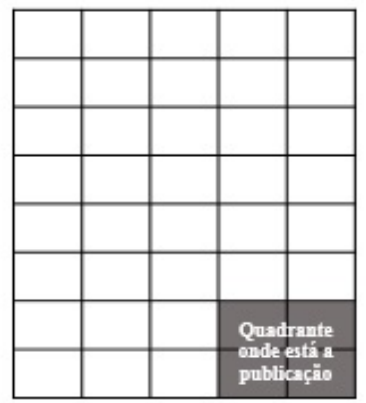

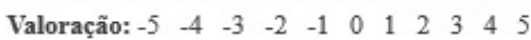

Enviado pela Assessoria: ( ) sim ( ) não

Forma de presença: ( ) primária ( ) secundária ( ) terciária

Sujeito da notícia: ( ) profissional ( ) instituição ( ) produtos/serviços

Mídia gratuita: R\$

Figura 3 - Modelo de ficha para coleta e descrição das informações (impresso). Fonte: elaborada pelo autor.

Quando formos analisar as inserções espontâneas - negativas e positivas - em rádio, também teremos de definir métricas as quais embasarão uma análise posterior à veiculação de algum fato relacionado à organização assessorada. Dados como nome do programa, radialista e horário de veiculação são exemplos de informações importantes, pois impactam diretamente na opinião pública e precisam ser considerados, além de outros números e elementos qualitativos:

- Nome da rádio

- Sintonia e frequência da rádio

- Data

Rev.Cad.Comun. Santa Maria, v.21, n.3, art 7, p. 133 de 143, set/dez.2017 
- Hora

- Jornalista responsável

- Radialista

- Programa

- Média de audiência

- Duração da divulgação/discussão

- Programa que antecedeu e sucedeu

- Súmula da abordagem

- Participação do ouvinte? ( ) sim ( ) não

- Comentários feitos pelos ouvintes

- Enfoque:( ) Positivo ( ) Neutro ( ) Negativo

- Impacto: ( ) Positivo ( ) Neutro ( ) Negativo

- Observação

- Repercussão em mídias sociais digitais: ( ) $\operatorname{sim}(\quad$ ) não

- Enfoque: ( ) Positivo ( ) Neutro ( ) Negativo

- Impacto: ( ) Positivo ( ) Neutro ( ) Negativo

- Observação

- Valoração: -5 -4 $\begin{array}{llllllllll}-3 & -2 & -1 & 0 & 1 & 2 & 3 & 4 & 5\end{array}$

- Enviado pela Assessoria: ( ) sim ( ) não

- Forma de presença: ( )primária ( ) secundária ( ) terciária

- Sujeito da notícia: ( ) profissional ( ) instituição ( ) produtos/ serviços

E para a análise do que foi veiculado em programas de televisão - tais como de jornalismo ou entretenimento - além de preferencialmente termos a gravação, precisamos avaliar o conteúdo e seus desdobramentos a partir de métricas quantitativas e qualitativas. A exemplo das sugeridas abaixo, necessitamos apreender informações pontuais e também considerar a repercussão a fim de propor ajustes na comunicação da organização ou contornar uma situação crítica: 
- Nome da emissora de TV

- Canal

- Data

- Hora

- Jornalista

- Programa

- Média de audiência

- Duração da divulgação/discussão

- Programa que antecedeu e sucedeu

- Súmula da abordagem

- Participação do telespectador?( ) sim ( ) não

- Comentários feitos pelos telespectadores

- Enfoque:( ) Positivo ( ) Neutro ( ) Negativo

- Impacto: ( ) Positivo ( ) Neutro ( ) Negativo

- Observação

- Repercussão em mídias sociais digitais? ( ) $\operatorname{sim}(\quad$ ) não

- Enfoque: ( ) Positivo ( ) Neutro ( ) Negativo

- Impacto: ( ) Positivo ( ) Neutro ( ) Negativo

- Observação

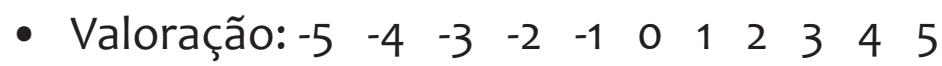

- Enviado pela Assessoria: ( ) sim ( ) não

- Forma de presença: ( ) primária ( ) secundária ( ) terciária

- Sujeito da notícia: ( ) profissional ( ) instituição ( )produtos/ serviços

\section{DO CLIPPING OPERACIONAL AO CLIPPING ESTRATÉGICO}

Como vimos, não podemos prescindir de uma avaliação quantitativa e qualitativa, sob pena de negligenciarmos aspectos bastante caros à nossa área, como a percepção subjetiva que os públicos têm a respeito da organização. Comumente, alguns equívocos são cometidos no momento de coleta, da identificação e da avaliação dos dados. Por isso, devemos levar em conta os seguintes erros que não podem ocorrer durante o processo de uma clippagem eficiente: 
1. Descontextualizar a matéria: ignorar as chamadas de noticiário televisivo ou radiofônico, manchetes de capa, contracapa, outras notícias ao redor, edição especial de jornal ou hotsite, complementos ou tema do caderno específico em que a notícia está publicada. O conteúdo pode ter relação positiva ou negativa com o negócio da organização, ou ainda, pode ser sobre um concorrente.

2. Identificar o "recorte" de maneira incompleta: além de saber em qual veículo de comunicação foi publicado algo sobre a marca, é preciso identificar de forma completa o material coletado, seja ele um recorte de jornal, print-screen de página da internet ou a gravação de TV e rádio. Alguns itens são indispensáveis para compará-lo com a presença de mídia do concorrente por exemplo.

3. Ser considerado como item isolado: o clipping só gera conhecimento e subsidia o trabalho de relações públicas quando analisado e comparado com o processo que lhe deu origem, a exemplo de releases enviados, eventos realizados, coletiva de imprensa, envolvimento numa crise, artigo de algum diretor, press-kit enviado, entrevista concedida, etc.

4. Confundir anúncio pago com matéria espontânea: anúncio pago é aquele oriundo de negociação entre os setores comerciais dos veículos de comunicação entre a agência ou a própria anunciante. Matéria espontânea consideramos aqui como sendo uma matéria oriunda de pauta sugerida pelo assessor de imprensa ou através da cobertura de eventos realizados pela empresa.

5. Empresas de monitoramento da mídia: devemos ter cuidado na contratação de empresas de monitoramento que não cruzam os dados quantitativos e qualitativos, além de não realizarem o tensionamento com os objetivos organizacionais e a estratégia global do cliente. É preciso levar em conta os indicadores de avaliação.

Após a coleta, identificação e descrição dos dados de uma matéria, nota, chamada, citação ou postagem devemos proceder a um processo de interpretação dos dados, levando em conta o plano de RP, seus objetivos

Rev.Cad.Comun. Santa Maria, v.21, n.3, art 7, p. 136 de 143, set/dez.2017 
e estratégia organizacionais. Para isso, algumas perguntas precisam ser respondidas pela equipe responsável pela assessoria de imprensa:

1. Por que o release foi aproveitado ou não pelos veículos?

2. E se tivéssemos feito em outro formato ou enviado a outros veículos/editorias/jornalistas?

3. Quais foram as táticas mais eficazes/eficientes?

4. O que teria acontecido se tivéssemos feito uma alteração no conteúdo do teaser, do release ou da cobertura?

5. Outras questões que a equipe considerar pertinentes.

Feito isso, diariamente - pois o clipping é uma atividade diária de acompanhamento e controle das práticas de RP - devemos proceder aos encaminhamentos necessários a partir do que foi publicado. As notícias publicadas podem gerar novas pautas para releases, releases de opinião ou de retratação, nota oficial, comunicado, entrevistas com responsáveis de área, evento especial, coletiva de imprensa, informações para o assessorado ou setor da empresa e outros desdobramentos possíveis.

O clipping não pode ser considerado apenas como um arquivo, mas sim como um arcabouço de informações relevantes, às quais os gestores da comunicação devem recorrer em momentos de tomada de decisões e de auditorias de imagem ou de mídia; por isso, deve ter sido apurado de forma completa a fim de embasar pesquisas, planos e novos posicionamentos. Simões (2006, p. 93) adverte que "Nesse mundo de incertezas, o ser humano busca dados que o levem à informação e daí às decisões eficazes. Esse fato faz pensar em como obter esses dados. A solução é encontrada no que se designa por Serviço de Inteligência". Dessa forma, as relações públicas se constituem num sistema estratégico que mune a organização de informações e, a partir delas, indica oportunidades, riscos e soluções.

\section{VEÍCULOS DE COMUNICAÇÃO EM MÍDIAS DIGITAIS}

No contexto de convergência midiática, os tradicionais veículos de comunicação aderiram às mídias digitais, seja como forma de se fazerem presentes onde hoje o seu leitor também está diariamente, seja para a expansão dos negócios, ou ainda com a finalidade de potencializarem as 
características dos novos formatos midiáticos, como a interação e a hipertextualidade. Nessa direção, atualmente eles possuem portais de notícias, blogs e têm perfis em mídias sociais digitais como Facebook, Twitter e Instagram, gerando conteúdos que também precisam da atenção dos profissionais de RP no momento de monitorarem e avaliarem a presença da organização na mídia.

Uma observação precisa ser feita. Clippagem não é monitoramento de presença digital da organização. O monitoramento de presença digital refere-se aos espaços e conteúdos oficiais das organizações, como blogs, hotsites, portais e outros perfis proprietários, sobre os quais temos determinado planejamento e controle do que é publicado. Com o clipping apenas monitoramos a presença da organização nos espaços digitais (e também impressos, radiofônicos e televisivos) dos veículos de comunicação, ou seja, o foco está nas matérias dos portais de notícias e nas postagens desses veículos em perfis nas mídias sociais digitais. A partir disso, realizamos a análise quantitativa, analisando número de compartilhamentos, "likes", comentários, acessos, etc. como também qualitativamente: destino dos links internos da matéria, o teor dos comentários e quem são esses interagentes que comentaram, "curtiram", responderam ou compartilharam (ver Figura 5). Nessa direção, faz-se necessário para a avaliação o mapeamento de sites, portais, mídias sociais digitais e blogs - de veículos pertencentes a grupos de comunicação, de coletivos, de veículos de comunicação alternativos e de jornalistas independentes. Para isso, além do acesso e da leitura diária, podemos contar com o uso de softwares gratuitos ou pagos como forma de termos em mãos instantaneamente uma publicação. Dois exemplos são os RSS Feeds', a partir dos quais recebemos em nosso e-mail a publicação momento após ir ao ar, e o Google Alertas², por meio do qual recebemos um alerta no e-mail sobre determinada publicação que programamos receber, a partir de palavras-chave relacionadas ao nosso negócio, tais como nomes de produtos/serviços ou o nome da organização e de seus líderes.

1 Dispositivo presente em sites que permite ao interagente assinar determinado conteúdo e recebê-lo em seu e-mail no momento que for publicado no site de origem.

2 Disponível em: <https://www.google.com.br/alerts> Acesso em: 09 fev. 2017.

Rev.Cad.Comun. Santa Maria, v.21, n.3, art 7, p. 138 de 143, set/dez.2017 


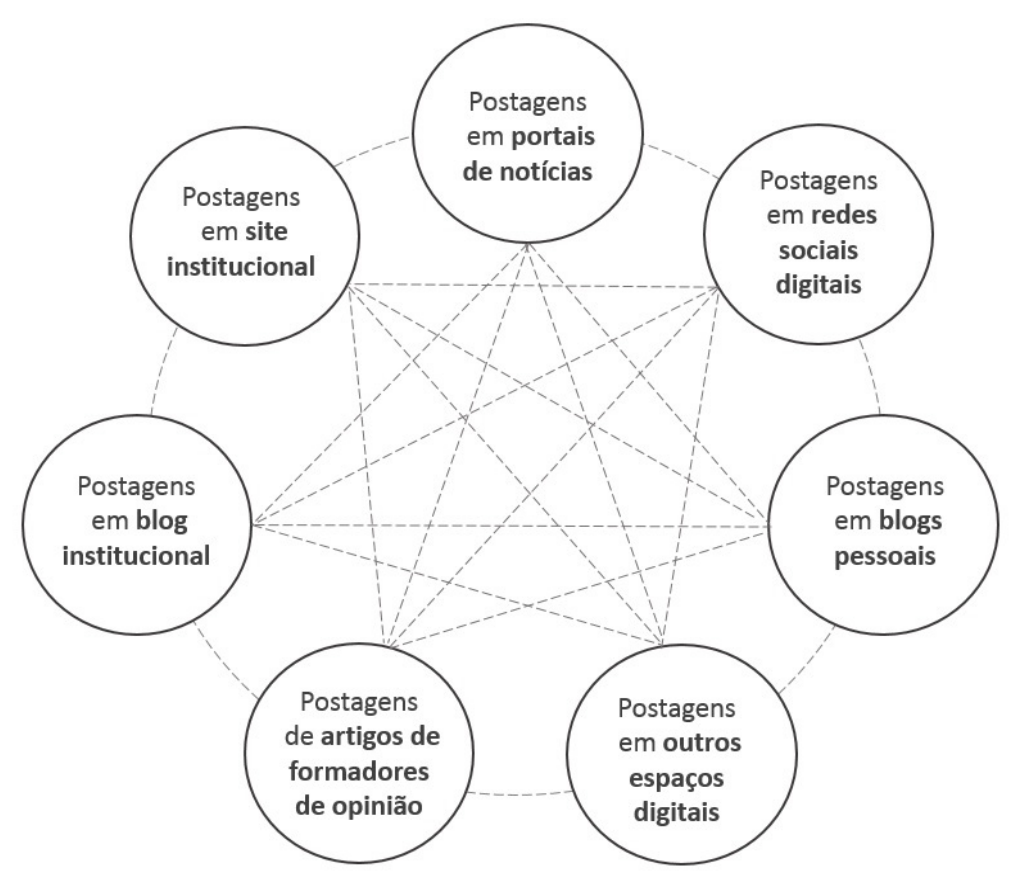

Figura 4 - Os fluxos de informação na ambiência da internet.

Fonte: Barichello; Machado (2015).

Resumindo, o monitoramento da presença da organização em mídias digitais é um processo em que são considerados os espaços digitais da organização e sua participação com perfis e páginas em mídias sociais digitais. A partir das postagens da organização em seu site, hotsite, portal ou em mídias sociais digitais é que realizamos a avaliação, diferentemente do clipping digital, em que o foco são os espaços digitais dos veículos de comunicação com presença na ambiência da internet. No monitoramento de presença organizacional, o trabalho demandará softwares específicos e equipe técnica capacitada para gerir a presença digital e os fluxos de informação característicos da internet, conforme Figura 4, diante da atuação dos interagentes, usuários-mídia que se relacionam com a marca e também produzem conteúdo, compartilham na rede e podem, inclusive, pautar a imprensa.

Levando em conta as características da internet - o alcance, a velocidade, a abrangência e a instantaneidade - o clipping em mídias digitais precisa ser realizado mais de uma vez ao dia, no mínimo duas, tendo em vista a atualização do conteúdo. Para isso, aconselhamos determinar os mesmos horários para todos os dias realizar este procedimento de coleta. Abaixo, apresentamos um modelo de ficha de clipping para a ambiência digital e, assim como o clipping de outras mídias, podem ser inseridos na coleta e descrição de outros dados de interesse de cada organização/ramo de ne- 
CADERNOS DE COMUNICAÇÃO

UNIVERSIDADE FEDERAL DE SANTA MARIA

gócio ou que tenhamos deixado de fora.

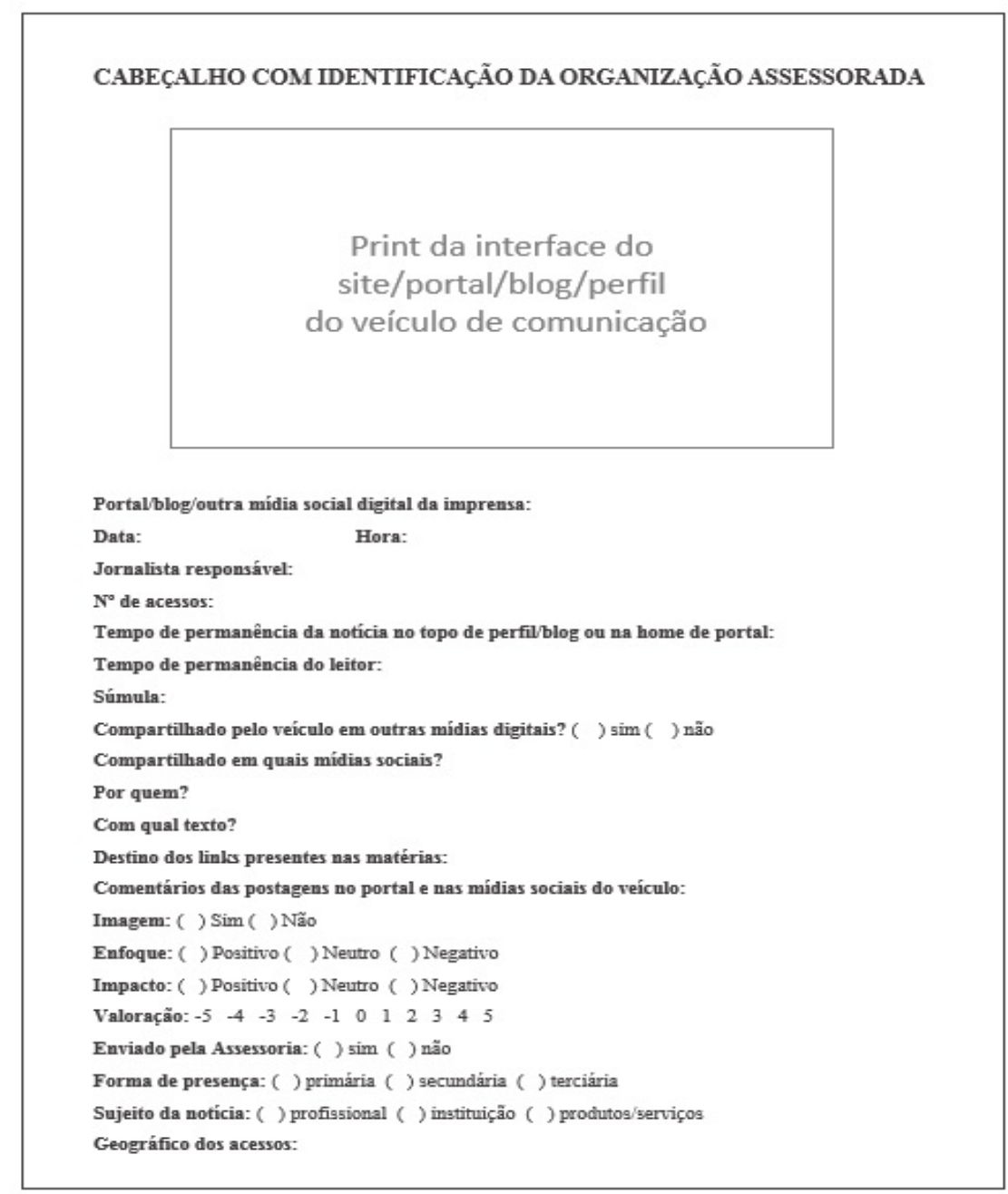

Figura 5 - Modelo de ficha para coleta e descrição das informações (digital). Fonte: elaborada pelo autor.

\section{RELATÓRIO ANUAL DE PRESENÇA NA MÍDIA}

Os esforços de RP empreendidos precisam ser apresentados de forma tangível aos gestores das organizações, sob forma de infográficos claros e atraentes, com vistas a avaliar as ações de comunicação realizadas, a pensar o processo comunicacional a longo prazo e a valorizar a área de Relações Públicas, ao mostrar quantitativa e qualitativamente os resultados alcançados (BARICHELLO, MACHADO, 2015). Para isso, faz-se mister criarmos um relatório anual por veículo de comunicação de cada tipo de mídia - impressa, radiofônica, televisiva e digital - a fim de demonstrar o retorno de investimento em assessoria de imprensa e, mais que isso, em ações de relações públicas.

De forma quantitativa, devemos atentar para os seguintes dados

Rev.Cad.Comun. Santa Maria, v.21, n.3, art 7, p. 140 de 143, set/dez.2017 
(além de outras informações definidas de acordo com a organização assessorada) que deem conta de avaliar os esforços por meio de números:

- Valor em mídia gratuita/espontânea a partir do cálculo de centimetragem

- \% de presença em editorias ou seções

- \% de presença em páginas/cadernos/programas especiais

- \% de presença em capa/contracapa/chamada

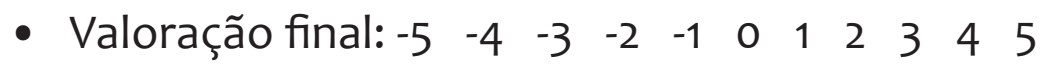

- \% de publicações geradas por pautas enviadas pela Assessoria

- ( )\% de sugestões de pauta x ( ) \% de publicações oriundas de releases

Qualitativamente, recorremos a fatores mais subjetivos e que demandam a descrição a partir de reflexão e interpretação profissional dos dados:

- Jornalistas mais receptivos às pautas enviadas

- Veículos de Comunicação mais receptivos às pautas sugeridas

- \% dos enfoque das publicações: (\%) Positivo (\%) Neutro (\%) Negativo

- \% do impacto: (\%) Positivo (\%) Neutro (\%) Negativo

- \% de sujeito da notícia: (\%) profissional (\%) instituição (\%) serviços

- \% da forma de presença: (\%) primária (\%) secundária (\%) terciária

- Oportunidades criadas

- Riscos detectados

- Crises geradas

- Comparação com os objetivos organizacionais

- Análise da concorrência no mesmo veículo

- Parecer com sugestões a partir da análise

Nesse sentido, com o auxílio de recursos gráficos próprios de softwares e com a organização lógica de ideias e o encadeamento de dados, o relatório anual a ser apresentado à Direção deve ser mais do que um instrumento de avaliação do que já foi implementado. Este documento deve ser claro e com linguagem acessível, trazer infográficos, tabelas, além de sugerir estratégias a serem implementadas, tanto para corrigir a presença 
na mídia quanto para potencializar os pontos positivos dela. Cabe, pois, ao profissional de caráter estratégico da área pesquisar, planejar, levar em conta os públicos com que se relaciona, assessorar de forma ágil, ética e competente, executar e acompanhar as ações, além de avaliar com minúcia, emitindo parecer técnico que contribua efetivamente para o alcance dos objetivos e da consecução da estratégia organizacional.

Precisamos lembrar que a avaliação por meio do clipping não é a única maneira de mensurar os resultados obtidos a partir do empreendimento de relacionamentos. O clipping apenas mede de forma parcial o relacionamento com a imprensa e a presença na mídia; não a relação com todos os públicos. O valor das relações públicas (GRUNIG, 2009) vai além desta técnica e de quantias financeiras, pois outros parâmetros precisam ser considerados, uma vez que a área gerencia relacionamentos de longo prazo e que são medidos com diversas metodologias quantitativas e qualitativas. Tangibilizar ativos intangíveis, tais como imagem e relacionamentos, não é tarefa simples, pois devemos levar em conta que nem sempre o esforço de relações públicas gera algo visivelmente positivo imediatamente, mas muitas vezes evita questões negativas tais como crises, greves e boicotes.

\section{CONSIDERAÇÕES FINAIS}

Em face do que assinalamos ao longo do estudo, por meio da reflexão e da proposição de um guia prático para auxiliar, de forma didática, os profissionais de relações públicas, reiteramos a importância de uma avaliação consistente das práticas desenvolvidas nas organizações, tendo suporte em abordagens quantitativa e qualitativa, a fim de dar conta do fenômeno comunicacional contemporâneo.

O valor das Relações Públicas precisa ser permanentemente solidificado. E a apresentação de resultados com pareceres técnicos bem lastreados - compostos pela contextualização dos dados e pela indicação de soluções para questões de caráter comunicacional - é uma das formas de tornarmos isso possível. Diante do exposto, com este estudo, esperamos contribuir com a prática de relações públicas em assessorias de imprensa, no sentido de que o profissional da área se torne cada vez mais estratégico e possibilite a consolidação de um serviço de inteligência (SIMÕES, 2006), contribuindo para a tomada de decisões nas organizações. 


\section{REFERÊNCIAS}

BARICHELLO, E.M.M.R.; MACHADO, J. Relações Públicas em novas mídias: o papel do monitoramento digital na comunicação das organizações. In: GONÇALVES, G.; LISBÔA, F.F. (orgs.) Novos media e novos públicos. Covilhã: LabCom, 2015.

BUENO, W. C. Auditoria de Imagem nas Organizações: teoria e prática. São Paulo: All Print Editora, 2012.

GRUNIG, J. E.; FERRARI, M. A.; FRANÇA, F. Relações Públicas: teoria, contexto e relacionamentos. 1. ed. São Caetano do Sul, SP: Difusão Editora, 2009.

KUNSCH, M. M. K. Planejamento de Relações Públicas na Comunicação Integrada. São Paulo: Summus, 2003.

SIMÕES, R. P. Informação, Inteligência e Utopia. Contribuições à Teoria de Relações Públicas. São Paulo: Summus, 2006.

\section{Jones Machado}

Doutor e Mestre em Comunicação e Bacharel em Relações Públicas pela UFSM. Pesquisador do Grupo de Pesquisa em Comunicação Institucional e Organizacional. Professor Adjunto do Departamento de Ciências da Comunicação da Universidade Federal de Santa Maria - Campus FW.

E-mail: jonesm2@outlook.com

RECEBIDO EM: 09/02/2017

ACEITO EM: 09/04/2017 